\title{
Knowledge, Attitudes, and Practices on African Animal Trypanosomosis and its vectors Among Small-Holder Farmers Neighbouring Arabuko Sokoke Forest Reserve, Kenya: A Cross Sectional Study
}

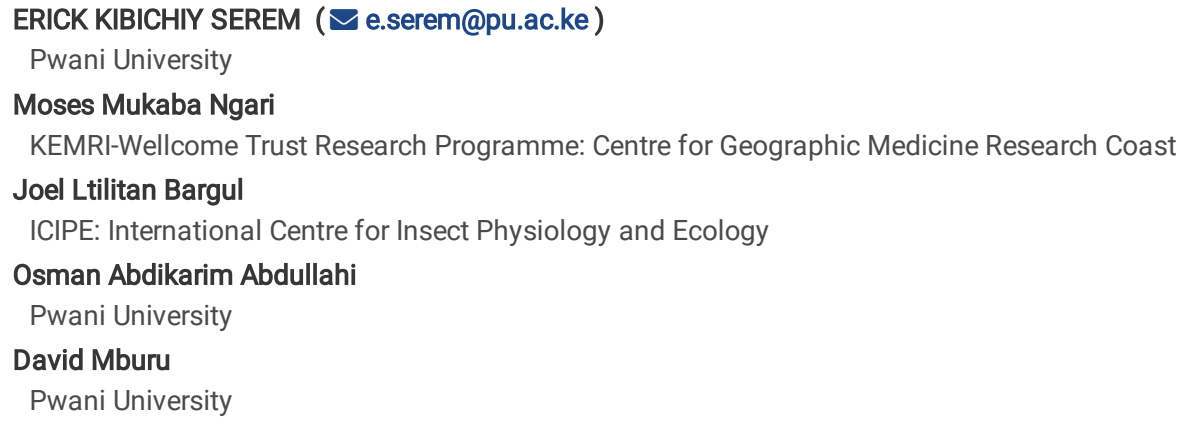




\section{Abstract}

Background: Animal African trypanosomosis (AAT) is a disease caused by several protozoan parasites transmitted by tsetse fly (genus Glossina). AAT causes massive losses to farmers due to the high cost of control measures and treatment of sick animals. This study aimed to assess the knowledge, attitudes and practices of the local community on tsetse flies and trypanosomosis and evaluate demographic factors associated with adequate knowledge of tsetse flies along Kenya coast.

Methods: We conducted a cross-sectional study between November and December 2017 among 404 cattle farmers living near the Arabuko-Sokoke Forest Reserve in Kilifi County. Structured questionnaires were used to collect data from randomly selected cattle rearing households. Descriptive statistics were used to analyze the local community's knowledge, attitudes, and practices regarding tsetse flies and trypanosomosis, and demographic factors associated with knowledge of tsetse flies were investigated using a logistic regression model.

Results: Of 404 study participants, 214 (53\%) were female, and 123 (30\%) were elderly (>55 years old). Majority (N=312, 77\%) were married, and 326 (81\%) had only primary education or none at all. Although majority of farmers $(\mathrm{N}=353,89 \%)$ knew the local name for tsetse fly and that they are about the size of a housefly ( $N=307,77 \%)$, only 65 (16\%) knew they transmit diseases to livestock, with $55 / 65(85 \%)$ identifying they transmit Nagana disease. Overall, only $16 \%$ of the study participants had adequate knowledge on tsetse flies and trypanosomosis. Being 15 to 24 years old (aOR 2.86 (95\% $\mathrm{Cl} 1.10-7.45)$ ) compared to those aged $>55$ years, secondary education (aOR $2.45(95 \% \mathrm{Cl} 1.42-4.21)$ ) and tertiary education level (aOR 3.78 (95\% $\mathrm{Cl} 1.53-9.31)$ ) compared to no education were significantly associated with higher odds of tsetse fly adequate knowledge. Unemployment (aOR 0.15 ( $95 \% \mathrm{Cl} 0.10-0.23)$ ) was significantly associated with lower odds of tsetse fly adequate knowledge when compared to self-employment.

Conclusion: Our findings suggest that farmers have poor understanding of trypanosomosis and its biological transmission by tsetse flies. Thus, training of livestock farmers will contribute to improved livestock health through better understanding of key livestock diseases, their vectors in transmission, and control.

\section{Introduction}

African trypanosomosis is a neglected tropical disease that is transmitted biologically by tsetse flies, (genus Glossina) and is found in thirty eight (38) subSaharan African countries including Kenya (1). Many studies have demonstrated the ability of biting flies such as Tabanids and Stomoxys to mechanically transmit Trypanosoma evansi and Trypanosoma vivax infections in horses, mules, camels, and cattle in Asia and South America (2, 3). Indeed, T. evansi is no longer capable of infecting the tsetse fly due to partial loss of mitochondrial DNA (4). Previous studies also showed that Trypanosoma congolense could be transmitted through mechanical means by the African tabanid Atylotus agrestis (5).

African trypanosomes are characterized by species-specific distinct cell morphometry and motility patterns (6) and have exceptionally broad host range causing infections in both humans (causing sleeping sickness or human African trypanosomosis, HAT) and in domestic and wild animals (nagana or surra in camels) (7). HAT is caused by two subspecies of Trypanosoma brucei, namely Trypanosoma brucei gambiense and T. b. rhodesiense. It is estimated that 70 million people are at risk of HAT infection in Africa (8). HAT is rare in Kenya, but AAT is prevalent in 38 of the 47 counties. Kenya is endemic for tsetse flies and nagana (1).

AAT is mainly caused by $T$. b brucei, T. evansi, T. congolense and T. equiperdum $(9,10)$. Trypanosoma vivax and T. congolense infect cattle, but can also cause disease in sheep, goats, pigs, horses, camels and dogs, among other wild animals like giraffe and waterbuck (9). Thus, AAT is one of the greatest impediment of livestock farming in Africa and gradually weakens the animals and reduces their draught power needed for cultivation of food and cash crops (11). Furthermore, it affects the livelihoods of farmers as it is one of the greatest causes of animal deaths leading to hunger and poverty (12). Further, the disease reduces the "living banks" reserves thus leading to inability to meet human social obligations such as dowry $(13,14)$. Due to AAT, Kenya incurs huge agricultural losses of up to approximately 20 billion Kenya shillings in lost revenue and costs for treatment or death of animals annually (15). The capital channeled towards procurement of veterinary drugs for treatment and management of livestock trypanosomosis could otherwise have served to improve the living standards of the people in endemic areas.

Arabuko-Sokoke Forest Reserve (ASFR) is the largest and most intact coastal forest in East Africa with an area of $420 \mathrm{~km}^{2}$ (16). This forest is infested by four species of tsetse flies namely Glossinabrevipalpis. G. Iongipennis, G. pallidipesand G. austeni (1). The human encroachment to formerly forested areas such as ASFR in search of arable land and pastures for their livestock has led to frequent exposures of humans and livestock with tsetse flies leading to transmission of diseases (17). Better understanding of livestock trypanosomosis and its transmitting vectors by communities living near tsetse belts have been identified as important barriers in disease control and prevention (18). Our study therefore sought to determine the status of community's knowledge, attitudes and practices towards tsetse flies and trypanosomosis commonly reported around the ASFR.

\section{Materials And Methods Study setting}

Kilifi County is one of the six counties in Kenya's coast region. The county lies between latitude $2^{\circ} 20^{\circ}$ and $4^{\circ} 0^{\circ}$ South, and between longitude $39^{\circ} 05^{\circ}$ and $40^{\circ}$ $14^{\circ}$ East. It borders Kwale County to the southwest, Taita Taveta County to the west, Tana River County to the north, Mombasa County to the south and Indian Ocean to the east. The County covers an area of $12,609.7 \mathrm{~km}^{2}$ and had an estimated population size of $1,453,787$ people in 2019 as projected in the Kenya Population and Housing Census of 2019 (19). The County has seven sub-Counties namely, Kilifi North, Kilifi South, Ganze, Malindi, Magarini, Rabai, and Kaloleni. Most livelihoods in Kilifi County are based on crop and livestock farming. The main livestock include cattle (Zebu), goats, sheep, poultry and beekeeping. Most of the livestock are indigenous breeds. Fishing is also an important livelihood activity especially for people near the shores (20). Our study 
area was purposely selected from three sub-Counties, namely Ganze, Kilifi North and Malindi, under which Arabuko-Sokoke Forest Reserve falls. The neighbouring area of the forest is mainly inhabited by the Giriama subtribe of the Mijikenda. Eight locations were selected as shown in Figure 1.

\section{Study population}

Participants sampled were aged $\geq 15$ years and have lived or are living around the Arabuko-Sokoke Forest Reserve in Kilifi County for at least previous one year. These participants keep or kept livestock in the past near the forest.

\section{Study Design and Data collection}

We conducted a community based cross-sectional study including randomly selected livestock farmers between November and December 2017. Before the study commenced, sensitization and research engagement meetings were held in presence of the County administrators including chiefs and local leaders and livestock keepers in order to inform them of the proposed research. In each of the sub counties, sub-locations whose boundaries were less than $5 \mathrm{~km}$ from ASFR boundary were included in the survey. All the 32 geographical locations bordering the Arabuko-Sokoke were considered for inclusion but included eight locations randomly selected. The eight locations included were: Dida, Nyari, Chumani, Matsangoni, Mida-Majaoni, Mijomboni, Mongotini and Ngerenya as shown in Figure 1. In each of the eight locations selected, households to be included were randomly selected proportional to population size of the location. Where a household was selected and did not rear livestock, it was substituted with the next household. Within a household, the questionnaire was administered to the household head or where not available, the most knowledgeable member of the household including older adolescents ( $\geq 15$ years) who mostly look after the livestock in this region. Study data were collected using structured questionnaire administered by the trained research assistants supervised by the lead investigator and in language understandable by the study participants.

\section{Study size}

In a small study of only 70 households in Tanzania, the prevalence of knowledge of tsetse flies was $90 \%$ (21). With this $90 \%$ prevalence knowledge of tsetse flies, level of significance of 0.05 and precision of $\mathbf{\pm 0 . 0 5}$, a sample size of 140 would be required. However, in our context we felt the $90 \%$ prevalence knowledge of tsetse flies was rather too high and thus estimated the study size using the $50 \%$ default prevalence adopted where there is no reliable data. With $50 \%$ prevalence, level of significance of 0.05 and precision of \pm 0.05 , a sample size of at least 385 would be required.

\section{Statistical analysis}

The data were analyzed using STATA software version 15.1 (StataCorp, College Station, TX, USA). Data about knowledge, attitudes and practices of the local community on tsetse flies and trypanosomosis disease were analyzed using descriptive statistics and reported frequencies and percentages. To examine demographic factors associated with knowledge of the tsetse flies, we used logistic regression analysis. Farmers who could: a) correctly identify the local name for tsetse flies, b) provide correct description of the tsetse flies and c) were able to identify that tsetse flies transmits disease to livestock were classified as having adequate knowledge of the tsetse flies (the dependent variable). We used backwards stepwise binary logistic regression analysis to determine demographic factors associated with knowledge of tsetse fly, retaining variables with $\mathrm{P}<0.1$ in the multivariable model but reported both crude and adjusted odds ratios and their respective $95 \%$ confidence intervals.

\section{Ethical consideration}

Permission to conduct the study was granted by the local leaders, livestock keepers and administration officers. Ethical approval to conduct the study was granted by Pwani University Ethics Review Committee (ref no: ERC/PhD/015/2016). Prior to commencement of the study, formal verbal and written informed consent were obtained from eligible participants and from the parents/guardians of the children under 18 years who participated in the study.

\section{Availability of data and materials}

The datasets used and/or analysed during the current study are available from the corresponding author on reasonable request.

\section{Results}

\section{Demographic characteristics}

A total of 404 participants were recruited in this study. Two hundred and fourteen (53\%) participants were female and approximately one-third ( $\mathrm{N}=123,30 \%)$ were above 55 years. Only 47 (12\%) were single, the rest were either married or were previously married but divorced, separated or widowed. There were 134 (33\%) participants with no education, 192 (48\%) with primary, 61 (15\%) with secondary and $16(4.5)$ with tertiary level of education. Only 41 (10\%) were employed, the rest were either self-employed in their farms or unemployed. The number of participants from each location are shown in Table 1. 


\begin{tabular}{|c|c|}
\hline Characteristics $(n=404)$ & $\mathrm{n}(\%)$ \\
\hline \multicolumn{2}{|l|}{ Sex } \\
\hline Male & $190(47)$ \\
\hline Female & $214(53)$ \\
\hline \multicolumn{2}{|l|}{ Age (in years) } \\
\hline 15 to 24 & $57(14)$ \\
\hline 25 to 34 & $78(19)$ \\
\hline 35 to 44 & $91(23)$ \\
\hline 45 to 54 & $55(14)$ \\
\hline Above 55 & $123(30)$ \\
\hline \multicolumn{2}{|l|}{ Marital status } \\
\hline Married & $312(77)$ \\
\hline Single & $47(12)$ \\
\hline Divorced & $4(1.0)$ \\
\hline Separated & $4(1.0)$ \\
\hline Widowed & $37(9.2)$ \\
\hline \multicolumn{2}{|l|}{ Level of education ${ }^{1}$} \\
\hline None & $134(33)$ \\
\hline Primary & $192(48)$ \\
\hline Secondary & $61(15)$ \\
\hline Tertiary & $16(4.0)$ \\
\hline \multicolumn{2}{|l|}{ Occupation ${ }^{1}$} \\
\hline Self-employed (farmer) & $184(46)$ \\
\hline Unemployed & $178(44)$ \\
\hline Employed (formal/informal) & $41(10)$ \\
\hline \multicolumn{2}{|l|}{ Location } \\
\hline Matsangoni & $47(12)$ \\
\hline Dida & $51(13)$ \\
\hline Chumani & $53(13$ \\
\hline Mijomboni & $53(13$ \\
\hline Mida & $54(13$ \\
\hline Ngerenya & $43(11)$ \\
\hline Kakuyuni & $53(13$ \\
\hline Nyari & $50(12)$ \\
\hline
\end{tabular}

\section{Knowledge Of Disease}

Three hundred and ninety-seven (98\%) participants reported to know a tsetse fly however, it is 353 (90\%) who could identify 'Imbu' as its local name. Majority $(\mathrm{N}=340,84 \%)$ participants reported tsetse flies live in bush areas while $74(18 \%)$ reported they lived in grassland. Three hundred and seven (76\%) reported tsetse flies are approximate the size of a housefly while 161 (40\%) reported tsetse flies have long mouthparts for biting. There were 16 (4.0\%) participants who did not know where livestock get into contact with tsetse flies, but 368 (91\%) identified forest as where livestock get into contact with tsetse flies. Two hundred and eighty-nine (72\%) reported tsetse flies' densities was highest during rainy season, 32 (7.9\%) during dry season, 28 (6.9\%) throughout the year and 48 (12\%) did not know. Thirty-two (7.9\%) did not know problems caused by tsetse flies to livestock. Only 65 (16\%) knew tsetse flies transmit diseases to livestock, 
of which only $4(6.1 \%)$ identified Nagana as the disease transmitted by tsetse flies. Health problems caused by the disease transmitted by tsetse reported by the 65 participant who knew it transmitted disease were: physical weakness ( $N=43,66 \%)$, cows looking slim $(N=21,32 \%)$, death $(N=16,25 \%)$ and low milk production ( $N=6,9.2 \%$ ) (Fig. 2). The source of information about tsetse flies and nagana disease was from practical knowledge through observation of tsetse flies among 50 (12\%) participants (Table 2). 
Table 2

Study participants' knowledge of diseases spread by tsetse fly.

\begin{tabular}{|c|c|}
\hline Knowledge $(\mathrm{N}=404)$ & n (\%) \\
\hline Knows tsetse fly & $397(98)$ \\
\hline \multicolumn{2}{|l|}{ What is the Local name for tsetse fly ${ }^{1}$} \\
\hline Imbu & $353(87)$ \\
\hline Mbungo & $10(2.5)$ \\
\hline Chibu & $33(8.2)$ \\
\hline \multicolumn{2}{|l|}{ Where to find tsetse fly } \\
\hline Grassland & $74(18)$ \\
\hline Bottom of valley & $9(2.2)$ \\
\hline Bush area & $340(84)$ \\
\hline Hilly areas & $2(0.5)$ \\
\hline \multicolumn{2}{|l|}{ How a tsetse fly looks like } \\
\hline More/less same size as housefly & $307(76)$ \\
\hline Long mouthparts for biting & $161(40)$ \\
\hline Brown/grey-brown/dark in colour & $92(23)$ \\
\hline Narrow in shape when at rest & $2(0.5)$ \\
\hline Body with darker and light patches & $39(9.7)$ \\
\hline \multicolumn{2}{|l|}{ Where do livestock get into close association with tsetse fly } \\
\hline Forest & $368(91)$ \\
\hline Riverine area & $5(1.2)$ \\
\hline Un-forested areas & $29(7.2)$ \\
\hline Don't know & $16(4.0)$ \\
\hline \multicolumn{2}{|l|}{ Time of the year with highest tsetse fly densities } \\
\hline Rainy season & $289(72)$ \\
\hline Dry season & $32(7.9)$ \\
\hline Throughout the year & $28(6.9)$ \\
\hline Don't know & $48(12)$ \\
\hline \multicolumn{2}{|l|}{ Problems caused by tsetse fly on livestock } \\
\hline Painful bites & $326(81)$ \\
\hline Distract grazing activities & $216(53)$ \\
\hline Transmit disease & $64(16)$ \\
\hline Don't know & $32(7.9)$ \\
\hline Tsetse flies transmit diseases to livestock & $65(16)$ \\
\hline \multicolumn{2}{|l|}{ Which disease? $(\mathrm{N}=65)$} \\
\hline Homa (fever) & $51(78)$ \\
\hline Nagana & $4(6.1)$ \\
\hline Don't know the disease & $10(15)$ \\
\hline \multicolumn{2}{|l|}{ Factors contributing to the spread of disease (trypanosomosis) $(N=65)$} \\
\hline Presence of tsetse flies & $59(91)$ \\
\hline Wild animals moving close to the security fence in search of water & $5(7.7)$ \\
\hline Don't know & $3(4.6)$ \\
\hline
\end{tabular}

${ }^{1-1}$ record missing data, ${ }^{2-6}$ records missing data (the participant did not respond to this question) 


\begin{tabular}{|c|c|}
\hline Knowledge $(\mathrm{N}=404)$ & n (\%) \\
\hline Presence of Arabuko Sokoke forest reserve next to the community & $3(4.6)$ \\
\hline \multicolumn{2}{|l|}{ Type of animals mostly affected by the disease $(\mathrm{N}=65)$} \\
\hline Cattle & $52(80)$ \\
\hline Goats/sheep & $28(43)$ \\
\hline \multicolumn{2}{|l|}{ Health problems caused by the disease in animals $(N=65)$} \\
\hline Physical weakness & $43(66)$ \\
\hline Loss of tail bush & $3(4.6)$ \\
\hline Swelling of lymph nodes & $7(11)$ \\
\hline Death & $16(25)$ \\
\hline Cows looking slim & $21(32)$ \\
\hline Laboured breathing & $7(11)$ \\
\hline Low milk production & $6(9.2)$ \\
\hline Animal becomes aggressive & $1(1.5)$ \\
\hline \multicolumn{2}{|l|}{ Source of information about tsetse flies and nagana disease ${ }^{2}$} \\
\hline School & $25(6.2)$ \\
\hline NGOs & $6(1.5)$ \\
\hline Extension officers & $12(3.0)$ \\
\hline Practical knowledge through observation of tsetse flies & $50(12)$ \\
\hline Never learnt & $304(75)$ \\
\hline Mass media (radio/television) & $1(0.2)$ \\
\hline
\end{tabular}

\section{Practices And Attitudes}

One hundred and nineteen (30\%) participants employed tsetse control techniques in order to prevent tsetse flies from infesting livestock (Table 3). The major tsetse control methods deployed included spraying livestock herds with insecticides $(N=61,51 \%)$ and use of drugs ( $N=42,35 \%)$. Some 55 ( $14 \%)$ of the participants did not know reasons for persistence of diseases transmitted by tsetse flies, whereas 36 (8.9\%) of the participants thought the reasons for persistence of tsetse-transmitted diseases was as a result of living near Arabuko-Sokoke Forest Reserve (Table 3). Three hundred and sixteen (78\%) participants did not know if recommended tsetse fly control methods are easy to use, 316 (78\%) effective and 320 (79\%) affordable (Table 3). 
Table 3

Practices and attitudes towards tsetse fly control

\begin{tabular}{|c|c|}
\hline Practices against the vector $(\mathrm{N}=404)$ & n (\%) \\
\hline Tried to prevent tsetse fly flying near animals & $119(30)$ \\
\hline \multicolumn{2}{|l|}{ Ways of preventing tsetse flies tried $(\mathrm{N}=119)$} \\
\hline Avoiding areas where tsetse flies are found & $11(9.2)$ \\
\hline Creating smoke near herd & $23(19)$ \\
\hline Spraying herd with insecticides & $61(51)$ \\
\hline Covering animal body with oil & $1(0.8)$ \\
\hline Use of drugs & $42(35)$ \\
\hline Traps and targets & $1(0.8)$ \\
\hline Clearing neighbouring bush & $21(18)$ \\
\hline \multicolumn{2}{|c|}{ Reasons for persistence of diseases transmitted by tsetse flies } \\
\hline Not educated on nagana & $9(2.2)$ \\
\hline Living near Arabuko Sokoke forest reserve & $36(8.9)$ \\
\hline No experts to educate farmers & $3(0.7)$ \\
\hline Presence of tsetse flies & $12(3.0)$ \\
\hline Do not know & $55(14)$ \\
\hline \multicolumn{2}{|c|}{ Recommended tsetse fly control methods are easy to use ${ }^{1}$} \\
\hline Agree & $69(17)$ \\
\hline Disagree & $13(3.2)$ \\
\hline Do not know & $316(78)$ \\
\hline \multicolumn{2}{|c|}{ Are recommended tsetse fly control methods effective? ${ }^{1}$} \\
\hline Agree & $72(18)$ \\
\hline Disagree & $10(2.5)$ \\
\hline Do not know & $316(78)$ \\
\hline \multicolumn{2}{|c|}{ Are recommended tsetse fly control methods cheap? ${ }^{1}$} \\
\hline Agree & $30(7.4)$ \\
\hline Disagree & $48(12)$ \\
\hline Do not know & $320(79)$ \\
\hline \multicolumn{2}{|c|}{ It is possible to control tsetse fly using recommended methods ${ }^{1}$} \\
\hline Agree & $68(17)$ \\
\hline Disagree & $16(4.0)$ \\
\hline Do not know & $314(78)$ \\
\hline \multicolumn{2}{|c|}{ Worth using recommended methods to control tsetse flies ${ }^{1}$} \\
\hline Agree & $67(17)$ \\
\hline Disagree & $11(2.7)$ \\
\hline Do not know & $320(79)$ \\
\hline \multicolumn{2}{|l|}{ Effect of tsetse flies infestation on family members } \\
\hline Bite & $64(16)$ \\
\hline Disease & $72(18)$ \\
\hline Financial loss & $11(2.7)$ \\
\hline
\end{tabular}

${ }^{1-6}$ records missing data (the participant did not respond to this question)

Page $8 / 14$ 


\begin{tabular}{|lc|}
\hline Practices against the vector $(\mathbf{N}=\mathbf{4 0 4})$ & $\mathbf{n}(\%)$ \\
\hline Don't know & $273(68)$ \\
\hline${ }^{1-6}$ records missing data (the participant did not respond to this question) \\
\hline
\end{tabular}

Association of demographic factors with knowledge of tsetse fly vector

Sixty-five (16\%. 95\% Cl 13 to $20 \%)$ participants had adequate knowledge about tsetse flies. In the univariate logistic regression models, females were associated with significantly lower odds of tsetse flies' knowledge (crude Odds ratio 0.39 ( $95 \% \mathrm{Cl} 0.19-0.80)$ ) compared to males (Table 4). Further, in comparison to participants with no formal education, both secondary and tertiary education levels were associated with higher odds of tsetse flies' knowledge; crude odds ratios $3.90(95 \% \mathrm{Cl} 1.47-10.32)$ and $5.58(95 \% \mathrm{Cl} 2.01-15.50)$ respectively. Compared to self-employed, unemployed was significantly associated with lower odds of tsetse flies' knowledge (crude odds ratio 0.23 (95\% Cl 0.09-0.59)) (Table 4).

Table 4

Association of demographic factors with the knowledge of tsetse flies.

\begin{tabular}{|c|c|c|c|c|c|}
\hline \multirow[t]{2}{*}{ Demographic characteristics } & \multirow[t]{2}{*}{ Knowledge of tsetse fly $(n=65)$} & \multicolumn{2}{|l|}{ Univariate analysis } & \multicolumn{2}{|l|}{ Multivariable analysis } \\
\hline & & Crude Odds Ratios & P-value & Adjusted Odds Ratios & P-value \\
\hline \multicolumn{6}{|l|}{ Sex } \\
\hline Male & $43(24)$ & Reference & & Reference & \\
\hline Female & $22(10)$ & $0.39(0.19-0.80)$ & 0.01 & $0.51(0.23-1.13)$ & 0.09 \\
\hline \multicolumn{6}{|l|}{ Age in years } \\
\hline Above 55 & $16(13)$ & Reference & & Reference & \\
\hline 45 to 54 & $9(16)$ & $1.31(0.61-2.82)$ & 0.49 & $1.18(0.51-2.73)$ & 0.70 \\
\hline 35 to 44 & $15(16)$ & $1.32(0.57-3.05)$ & 0.52 & $1.05(0.45-2.43)$ & 0.92 \\
\hline 25 to 34 & $13(17)$ & $1.34(0.59-3.03)$ & 0.49 & $1.15(0.51-2.56)$ & 0.74 \\
\hline 15 to 24 & $12(21)$ & $1.78(0.67-4.74)$ & 0.25 & $2.86(1.10-7.45)$ & 0.03 \\
\hline \multicolumn{6}{|l|}{ Marital status } \\
\hline Married & $51(16)$ & Reference & & & \\
\hline Single & $11(23)$ & $1.56(0.51-4.84)$ & 0.44 & 9 & \\
\hline Divorced & $1(25)$ & $1.71(0.12-24.2)$ & 0.69 & 9 & \\
\hline Separated & $1(25)$ & $1.71(0.15-19.5)$ & 0.67 & 9 & \\
\hline Widowed & $1(2.7)$ & $0.14(0.02-1.05)$ & 0.06 & 9 & \\
\hline \multicolumn{6}{|l|}{ Level of education } \\
\hline None & $13(9.7)$ & Reference & & Reference & \\
\hline Primary & $28(15)$ & $1.59(0.92-2.73)$ & 0.10 & $1.12(0.63-1.98)$ & 0.70 \\
\hline Secondary & $18(30)$ & $3.90(1.47-10.3)$ & 0.006 & $2.45(1.42-4.21)$ & 0.001 \\
\hline Tertiary & $6(38)$ & $5.58(2.01-15.5)$ & 0.001 & $3.78(1.53-9.31)$ & 0.004 \\
\hline \multicolumn{6}{|l|}{ Occupation } \\
\hline Self-employed & $44(24)$ & Reference & & Reference & \\
\hline Unemployed & $12(6.7)$ & $0.23(0.09-0.59)$ & 0.002 & $0.15(0.10-0.23)$ & $<0.001$ \\
\hline Employed & $9(22)$ & $0.89(0.40-1.99)$ & 0.79 & $0.47(0.15-1.48)$ & 0.20 \\
\hline
\end{tabular}

In the multivariable regression analysis, being 15 to 24 years old (aOR $2.86(95 \% \mathrm{Cl} 1.10-7.45)$ ) compared to those aged $>55$ years, secondary education (aOR $2.45(95 \% \mathrm{Cl} 1.42-4.21))$ and tertiary education level (aOR $3.78(95 \% \mathrm{Cl} 1.53-9.31))$ compared to no education were significantly associated with higher odds of tsetse fly knowledge. Compared to self-employed, unemployed (aOR $0.15(95 \% \mathrm{Cl} 0.10-0.23)$ ) was associated with significantly lower odds tsetse fly knowledge (Table 4). No other demographic factors were associated with tsetse fly knowledge.

\section{Discussion}


The effectiveness of disease control measures implemented by a community is largely determined by their knowledge, attitudes, and practices regarding the disease and, in this case, the vector. Understanding how AAT affects cattle owners and how they handle the disease is vital to developing effective, locallyadapted control programmes (22). Community participation in tsetse control activities ensures sustainability of the programmes especially if the community members and extension officers are involved in design of the programmes (23).

Overall, we found only $16 \%$ of the livestock-keeping communities living near Arabuko Sokoke Forest Reserve had adequate knowledge on tsetse flies and animal African trypanosomosis. Similar studies in Ethiopia and Tanzania around Baro-Akobo and Gojeb river basins, and Serengeti National Reserve, respectively, found out that the communities around the reserve had limited knowledge of tsetse flies and trypanosomosis (24)(21). This is in contrast to other studies where $23.1 \%$ of the farmers could associate the causal association between tsetse flies and trypanosomosis among communities surrounding Shimba Hills National Reserve (25). In other studies in Tanzania, $90 \%$ of the respondents interviewed in communities surrounding Serengeti national park (27) (21) had adequate knowledge of trypanosomosis. However, earlier studies showed that people living around Serengeti National Park in Tanzania were knowledgeable about tsetse flies and human African trypanosomosis (27) and the tsetse flies (26) while those in Mateu district in Tanzania were more knowledgeable in AAT than HAT (28). The reason for the higher level of knowledge for in Serengeti may be attributed to the high number of respondents (45\%) who had attained secondary education compared to $19 \%$ in this study for those with secondary and post-secondary education while the participants without formal education together with their counterparts with primary level education comprising of $81 \%$ of the respondents. People who are familiar with the clinical signs of the disease are more likely to seek assistance from the veterinary officers because they can identify the sick animals early before their body conditions deteriorate. Furthermore, unlike other studies in which male predominance is high, particularly in the active age groups (21)(29), this study was predominated by women (53\%) and people above 55 years (44\%).

The huge difference in knowledge gap noted in this study could be attributed to the fact that studies by (21) occurred just after recent outbreaks which were followed by awareness campaigns. The other reason for the difference in knowledge gap could be the population sampled. Another study in western part of Serengeti reported $95 \%$ of the respondents were knowledgeable on tsetse flies and trypanosomosis (26). The study participants in Serengeti were predominantly male unlike the present study which was dominated by women, who dominate livestock keeping among the Giriama community. The higher number of older people sampled in this study may be due to their preference to live in the villages, unlike the younger educated generation with preference to live and work in cities. (26)

Furthermore, the limited knowledge by the participants in this study, on the vector and the disease transmitted, influenced their attitude towards prevention and control measures. The vast majority of the respondents (98\%) assumed that they knew tsetse flies, but most of them were unable to describe tsetse fly or could not distinguish it from other biting flies. The respondents' inability to describe a tsetse fly raises questions about their certainty that tsetse fly bites cause disease. They did, however, realized that contact with tsetse flies occurs primarily in the forest while the animals are grazing. Secondary and tertiary education were associated with higher knowledge of AAT compared to primary education and no formal education. This could be attributed to the knowledge acquired in post primary education. In one section of Dida location, where the wild animals watering point is at the edge of the forest near the village, the respondents noted that contact with tsetse flies occurred when the animals, especially elephants go to the watering point to drink water. Indeed, knowledge of tsetse flies and measures of trypanosomosis control have been shown as important factors influencing the community's willingness to contribute resources and participate in control activities (23). Indeed, communities with a low level of education are principally vulnerable, and could be difficult to integrate them into control programmes (30).

Regarding the description of the disease transmitted by tsetse flies, most of the respondents could not describe the clinical signs of an animal suffering from trypanosomosis. Among the Giriama community, any form of sickness is locally referred to as "homa" which means fever. Many in this community believe that tsetse fly bites cause "homa" in both humans and livestock. They also noted that hybrid animals such as Friesian and Ayrshire are the most affected, while a cross breed with the Zebu and Borana cattle (local breeds) are more tolerant to bites by tsetse flies. Indeed the Maasai Zebu and the Orma Boran breeds have been shown to be more resistant to trypanosomosis over other local breeds such as the Galana Boran and the exotic breeds (31). Other African local cattle breeds such as the Baoulé, Zebu, Ndama and Ndama/Baoulé crosses have various degrees of resistance to African trypanosomosis (32).

Compared with the unemployed and the uneducated, educated and employed farmers were found to be implementing the recommended methods of tsetse control. The attitude of the participants without formal education further influenced their use of control methods for tsetse and trypanosomosis. Most uneducated people did not know the recommended methods for controlling tsetse and trypanosomosis and therefore could not use them. This is in agreement with other studies where knowledge of disease influenced preventive practices (33). Other studies, on the other hand, have shown that disease knowledge does not always correlate to practice, with vector management strategies being lower than disease knowledge (30). Some of the participants in this study were aware on the control measures but did not believe it was worthwhile to use them. Others were aware of the control measures but could not afford to implement them. We also noticed that some of the farmers were dipping or spraying their livestock, but they were unaware that acaricides could prevent tsetse flies from biting livestock. While this study did not investigate the types of acaricides used by farmers living around Arabuko Sokoke Forest reserve, other studies in Uganda have shown that farmers may use acaricides that are resistant to tsetse flies but only effective against ticks (34). Although the County Government of Kilifi has dips, most of them were non-functional due to challenges such as water shortages and overdependence on the government to run the dips. Subsequently, tsetse control groups were formed in all sub-Counties and were supplied with pumps and pyrethroid-based acaricides that are effective against ticks and tsetse to supplement the dipping service.

In comparison to the reference group of 15-24 year olds, the majority of people, particularly those over 55 years old, did not know whether the recommended tsetse control measures were effective or worth using at all. As the head of homesteads, they also felt that the control measures were costly. This could be attributed to the fact that this group supports families and thus contributes money for tsetse control compared to the youth between 15 to 24 years.

Furthermore, household heads preferred keeping goats over cattle because the cost of keeping cattle is high due to the requirement of regular dipping whereas 
goats are more resistant to trypanosomosis. The fact that goats are more resistant to trypanosomosis may explain the low prevalence of trypanosomosis among caprines (35) (36).

\section{Study Strengths And Limitations}

To the best of our knowledge, this is the first study to assess the knowledge, attitudes and practices of communities surrounding Arabuko Sokoke Forest Reserve on tsetse flies and animal African trypanosomosis. KAP surveys help to identify gaps in community tsetse control measures, that, if filled, will make it easier for them to participate in AAT control activities and, in turn, increase tsetse control coverage and efficacy. This study forms a baseline for future studies.

The study relied on reported data from the farmers which could be subject to reporting bias. Some farmers from selected households did not keep livestock and were excluded in this study, however, these were very few. The cross-sectional survey measured knowledge, attitude and practice at the time the study, which may have changed over time.

\section{Conclusion And Recommendations}

The gap identified in this study in the knowledge of tsetse flies and trypanosomosis among the community surrounding ASRF, especially women who are the majority of livestock keepers, should inform prioritization of this group in control tsetse and trypanosomosis control programs. Public sensitization on tsetse control may be done through the county agricultural extension services or organizations such as the 'Friends of Arabuko Sokoke Forest'.

\section{Declarations}

\section{Funding:}

This work was supported by the Pwani University Research Fund (PURF). Grant no PURF/02/2017.

The views expressed in this publication are those of the author(s) and not necessarily those of funders. The funders had no role in study design, data collection and analysis, decision to publish, or preparation of the manuscript.

\section{Acknowledgements}

We thank the chiefs, village leaders, livestock farmers and the director of veterinary services of Kilifi County, Dr. Cornel Malenga, whose cooperation made the accomplishment of this study possible. We also thank Dr. Noah Maritim and Ms. Annie Willets for their direct or indirect support during the preparation for/and data collection.

\section{Author contributions:}

Conceived and designed the experiments: EKS, OAA, JLB, DMM.

Performed the experiments: EKS.

Analyzed the data: EKS, MMN, OAA, JLB, DMM.

Contributed reagents/materials/analysis tools: MMN, OAA, JLB, DMM.

Wrote the paper: EKS, MMN, OAA, JLB, DMM.

\section{Competing interests}

The authors declare that they have no competing interests

\section{References}

1. KENTTEC. kenttec [Internet]. KENTTEC. 2017. Available from: http://www.kenttec.or.ke/index.php/homepage/tsetse-trypanosomiasis-problem.

2. Mihok S, Maramba O, Munyoki E, Kagoiya J. Mechanical transmission of Trypanosoma spp. by African Stomoxyinae (Diptera: Muscidae). Trop Med Parasitol. 1995 Jun;46(2):103-5.

3. Jones TW, Dávila AMR. Trypanosoma vivax - Out of Africa. Trends Parasitol. 2001;17(2):99-101.

4. Lai DH, Hashimi H, Lun ZR, Ayala FJ, Lukes J. Adaptations of Trypanosoma brucei to gradual loss of kinetoplast DNA: Trypanosoma equiperdum and Trypanosoma evansi are petite mutants of T. brucei. Proc Natl Acad Sci U S A. 2008;105(6):1999-2004.

5. Desquesnes M, Dia ML. Mechanical transmission of Trypanosoma congolense in cattle by the African tabanid Atylotus agrestis. Exp Parasitol. 2003;105(3-4):226-31.

6. Bargul JL, Jung J, McOdimba FA, Omogo CO, Adung'a VO, Krüger T, et al. Species-Specific Adaptations of Trypanosome Morphology and Motility to the Mammalian Host. PLoS Pathog. 2016;12(2):1-29.

7. Capewell P, Cooper A, Clucas C, Weir W, Macleod A. A co-evolutionary arms race: trypanosomes shaping the human genome, humans shaping the trypanosome genome. 2015. 
8. Simarro PP, Cecchi G, Franco JR, Paone M, Diarra A, Ruiz-Postigo JA, et al. Estimating and Mapping the Population at Risk of Sleeping Sickness. PLoS Negl Trop Dis. 2012;6(10).

9. Auty H, Anderson NE, Picozzi K, Lembo T, Mubanga J, Hoare R, et al. Trypanosome Diversity in Wildlife Species from the Serengeti and Luangwa Valley Ecosystems. PLoS Negl Trop Dis. 2012;6(10).

10. Giordani F, Morrison LJ, Rowan TG, De Koning HP, Barret MP. The animal trypanosomiases and their chemotherapy: a review. Parasitology [Internet]. 2016;1-28. Available from: http://www.journals.cambridge.org/abstract_S0031182016001268.

11. Steverding D. The history of African trypanosomiasis. Parasit Vectors [Internet]. 2008;1(1):3. Available from: http://www.pubmedcentral.nih.gov/articlerender.fcgi? artid=2270819\&tool=pmcentrez\&rendertype=abstract\%5Cnhttp://www.ncbi.nlm.nih.gov/pubmed/18275594\%5Cnhttp://www.pubmedcentral.nih.gov/artic artid=PMC2270819.

12. Van Eenennaam AL, Young AE. Animal agriculture and the importance of agnostic governance of biotechnology. Agric Food Secur [Internet]. 2015;4(1):21. Available from: http://www.agricultureandfoodsecurity.com/content/4/1/21.

13. Swallow B. Impacts of trypanosomiasis on African agriculture. Int Livest Res Institute, Nairobi, Kenya [Internet]. 1999;1-46. Available from: http://www.cabdirect.org/abstracts/20003010139.html.

14. Meyer A, Holt HR, Selby R, Guitian J. Past and Ongoing Tsetse and Animal Trypanosomiasis Control Operations in Five African Countries: A Systematic Review. PLoS Negl Trop Dis [Internet]. 2016;10(12):e0005247. Available from: http://dx.plos.org/10.1371/journal.pntd.0005247.

15. Nthiwa DM, Odongo DO, Ochanda H, Khamadi S, Gichimu BM. Trypanosoma Infection Rates in Glossina Species in Mtito Andei Division, Makueni County, Kenya. J Parasitol Res. 2015;2015:1-8.

16. Kenya Forest Service. Kenya Forest Service - Kenya Forest Service [Internet]. 2017. Available from: http://www.kenyaforestservice.org/index.php? option=com_content\&view=article\&id=72\&ltemid=488.

17. Rutto JJ, Osano O, Thuranira EG, Kurgat RK, Odenyo VAO. Socio-Economic and Cultural Determinants of Human African Trypanosomiasis at the Kenya Uganda Transboundary. PLoS Negl Trop Dis. 2013;7(4).

18. Tshimungu K, Kalambayi BB, Kiyombo M, Okenge LN, Mol PD. Knowledge, behaviours, practices and beliefs regarding human African trypanosomiasis (HAT) among inhabitants of Kinshasa (Democratic Republic of Congo). Sante. 2008;18:141-7.

19. KNBS. 2019 Kenya Population and Housing Census Volume 1: Population by County and Sub-County [Internet]. Vol. I, 2019 Kenya Population and Housing Census. 2019. 49 p. Available from: https://www.knbs.or.ke/?wpdmpro=2019-kenya-population-and-housing-census-volume-i-population-bycounty-and-sub-county.

20. MoALF. Climate Risk Profile for Kilifi County. Kenya County Climate Risk Profile Series; 2016.

21. Mwaseba DL, Kigoda KJ. Knowledge, attitude, and practices about tsetse control among communities neighbouring Serengeti National Park, Tanzania. Heliyon [Internet]. 2017;3(6):e00324. Available from: http://dx.doi.org/10.1016/j.heliyon.2017.e00324.

22. Holt HR, Selby R, Mumba C, Napier GB, Guitian J. Assessment of animal African trypanosomiasis (AAT) vulnerability in cattle-owning communities of subSaharan Africa. Parasit Vectors [Internet]. 2016;9(1):53. Available from: http://ovidsp.ovid.com/ovidweb.cgi?

$T=J S \& P A G E=$ reference \&D=prem\&NEWS=N\&AN=26825496.

23. Sindato C, Kimbita EN, Kibona SN. Factors influencing individual and community participation in the control of tsetse flies and human African trypanosomiasis in Urambo District, Tanzania. Tanzan J Health Res. 2008;10(1):20-7.

24. Seyoum Z, Terefe G, Ashenafi H. Farmers' perception of impacts of bovine trypanosomosis and tsetse fly in selected districts in \{Baro-Akobo\} and Gojeb river basins, Southwestern Ethiopia. \{BMC\} Vet Res [Internet]. 2013;9(1):214. Available from: http://dx.doi.org/10.1186/1746-6148-9-214.

25. Machila N, Wanyangu SW, McDermott J, Welburn SC, Maudlin I, Eisler MC. Cattle owners' perceptions of African bovine trypanosomiasis and its control in Busia and Kwale Districts of Kenya. Acta Trop. 2003;86(1):25-34.

26. Mechtilda B, Gamba N, Sebastian M. Evaluation of knowledge, attitude and practices of agro-pastoralists on tsetse fly(Glossina sp.) in Western Serengeti Tanzania. J Vet Med Anim Heal. 2016;8(11):169-75.

27. Kinung'hi SM, Malele II, Kibona SN, Matemba LE, Sahani JK, Kishamawe C, et al. Knowledge, attitudes and practices on tsetse and sleeping sickness among communities living in and around Serengeti National Park, Tanzania. Tanzan Health Res Bull. 2006 Sep;8(3):168-72.

28. Malulu DJ, Kimbita EN, Tuntufye HN, Kinung'hi S, Nyingilili HS, Lyaruu E, et al. Assessment of community knowledge, attitude and practices for sustainable control of tsetse and tsetse-borne trypanosomosis in meatu district, Tanzania. Livest Res Rural Dev. 2017;29(5).

29. Uba BV, Aliyu A, Abubakar A, Uba SA, Gidado S, Edukugho A, et al. Knowledge and prevalence of human african trypanosomiasis among residents of kachia grazing reserve, Kachia local government area, Kaduna state, Nigeria, 2012. Pan Afr Med J. 2016;23:1-8.

30. Kumaran E, Doum D, Keo V, Sokha L, Sam BL, Chan V, et al. Dengue knowledge, attitudes and practices and their impact on community-based vector control in rural Cambodia. PLoS Negl Trop Dis. 2018;12(2):1-16.

31. Mwangi EK, Stevenson P, Gettinby G, Reid SWJ, Murray M. Susceptibility to trypanosomosis of three Bos indicus cattle breeds in areas of differing tsetse fly challenge. Vet Parasitol. 1998;79(1):1-17.

32. Roelants GE, Fumoux F, Pinder M, Queval R, Bassinga A, Authie E. Identification and selection of cattle naturally resistant to African trypanosomiasis. Acta Trop. 1987 Mar;44(1):55-66.

33. Alobuia WM, Missikpode C, Aung M, Jolly PE. Knowledge, Attitude, and Practices Regarding Vector-borne Diseases in Western Jamaica. Ann Glob Heal [Internet]. 2015;81(5):654-63. Available from: http://dx.doi.org/10.1016/j.aogh.2015.08.013. 
34. Bardosh K, Waiswa C, Welburn SC. Conflict of interest: Use of pyrethroids and amidines against tsetse and ticks in zoonotic sleeping sickness endemic areas of Uganda. Parasites and Vectors [Internet]. 2013;6(1):1. Available from: Parasites \& Vectors.

35. Oladele OI, Adenegan KO. Implications of small ruminant farmer's socio-economic characteristics for extension services in South Western Nigeria. In: Ologhobo AD, lyayi EA, editors. The Nigeria Livestock Industry in the 21st Century. Lagos: Animal Science Association of Nigeria; 1998. pp. $243-6$.

36. Mekata H, Konnai S, Simuunza M, Chembensofu M, Kano R, Witola WH, et al. Prevalence and Source of Trypanosome Infections in Field-Captured Vector Flies (Glossina pallidipes) in Southeastern Zambia. J Vet Med Sci. 2008;70(9):923-8.

\section{Figures}

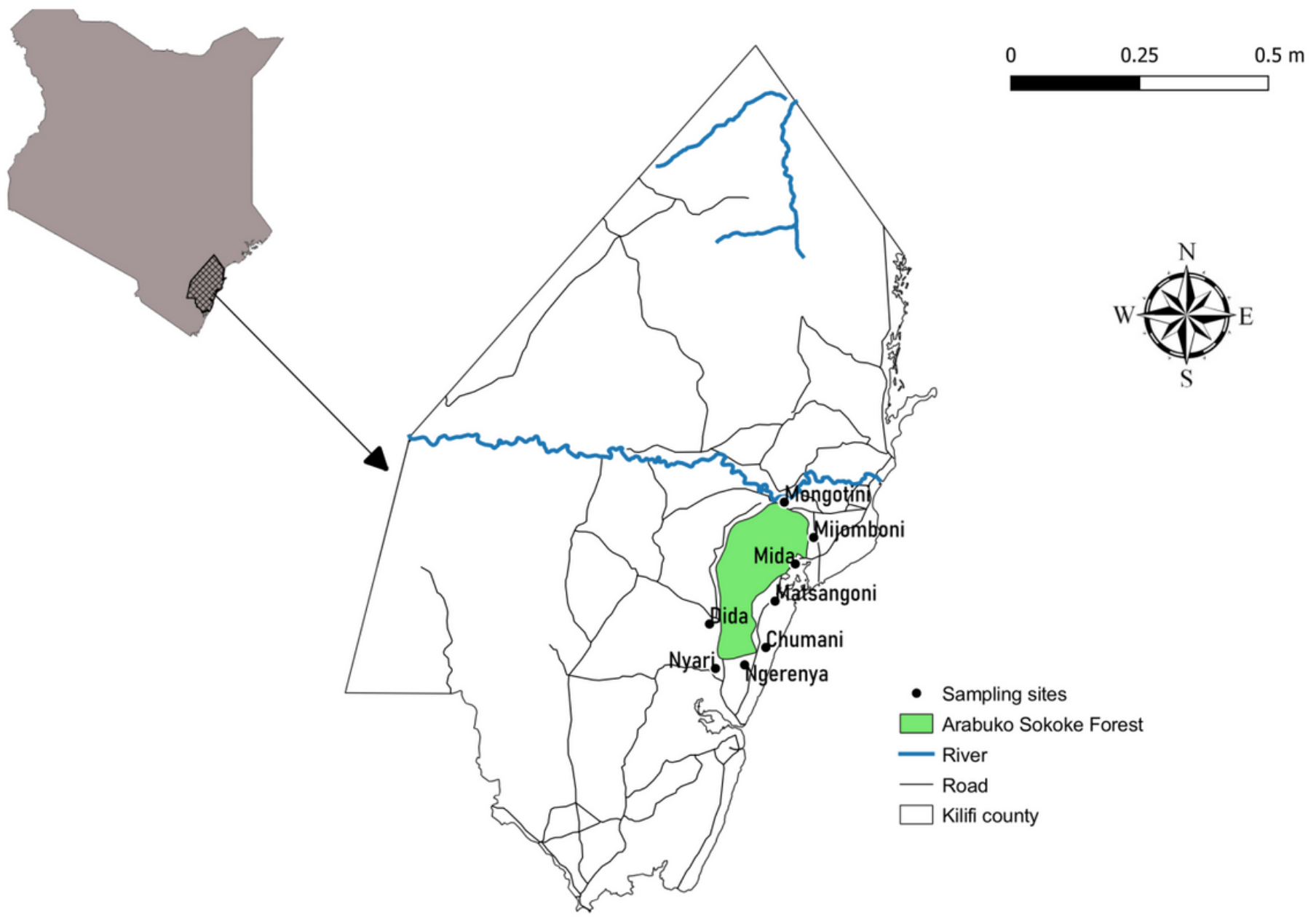

\section{Figure 1}

Selected sampling sites neighbouring Arabuko-Sokoke Forest Reserve in Kilifi County, Kenya. Eight (8) sampling sites were selected around ASFR 


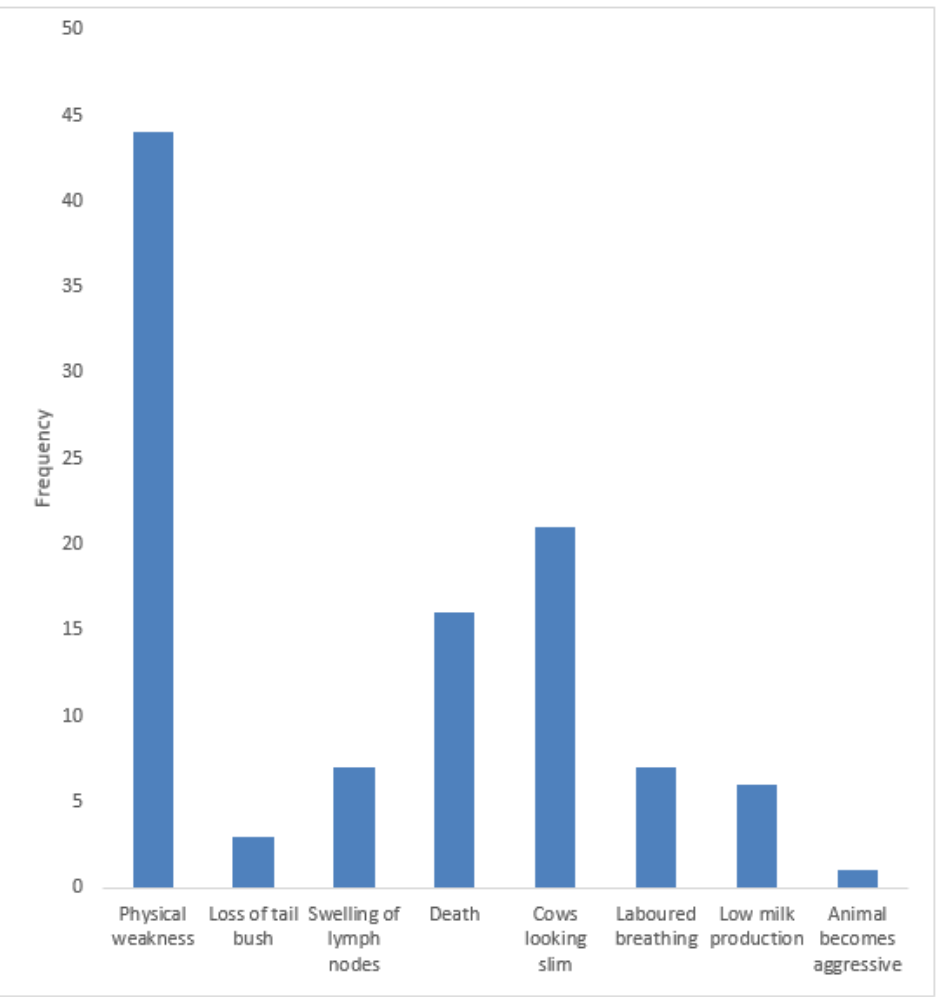

Figure 2

Health problems caused by the disease transmitted by tsetse flies in animals $(\mathrm{N}=65)$.

\section{Supplementary Files}

This is a list of supplementary files associated with this preprint. Click to download.

- Graphicalabstract.jpg 